This paper reports a study into the formation of the phase composition, structure, and properties of arc welding coatings by the flux-cored electrode materials from the $\mathrm{Fe}-\mathrm{Mo}-\mathrm{B}-\mathrm{C}$ system. The welding alloys were applied using the flux-cored arc welding (FCAW) electrodes, which consisted of a shell made from the low-carbon steel filled with a reaction powder mixture that contained boron carbide and molybdenum in a ratio of 1:1.

The calculation of the phase composition of alloys that correspond to the surfaced layers by a CALPHAD method using the Thermo-Calc OpenCalphad software shows that under the equilibrium conditions the boride phases of molybdenum and ferrite cannot co-exist. The main phase of such alloys is a $\mathrm{FeMo} \mathrm{B}_{2}$ compound, which forms the eutectics with austenite. Given that the eutectic structures with borides are characterized by high brittleness, the introduction of components was conducted in the form of a reaction mixture in order to obtain the in situ formed boride phases in the form of separate structural components.

Analysis of the results of studying the microstructure and phase composition of coatings reveals that they consist of three main structural components: the eutectic $\left(\mathrm{FeMo}_{2} \mathrm{~B}_{2}+\right.$ ferrite $)$ and the grains of molybdenum tetraboride $\mathrm{MoB}_{4}$. Thus, under the conditions of arc welding using the reaction mixture, an irregular structure is formed, which is favorable in terms of ensuring wear resistance due to the high microhardness of $\mathrm{MoB}_{4}>27 \mathrm{GPa}$.

The hardness of the coatings obtained is at the level of 63-65 HRC, and the wear resistance is higher compared to standard high-chromium alloys (grades T620 and T590) by 2-2.5 times. This makes it possible to recommend the coating of a given system for hardfacing the working surfaces of equipment in the coal, processing, woodworking industries, etc., where abrasive wear is the dominant type of surface wear

Keywords: powder wire, hardfacing, molybdenum borides, reaction synthesis, abrasive wear

\section{$-\square$}

Received date 10.05.2020

Accepted date 20.06.2020

Published date 31.08.2020
UDC 669.018 .95

DOI: $10.15587 / 1729-4061.2020 .206568$

\title{
IN SITU FORMATION OF MOLYBDENUM BORIDES AT HARDFACING BY ARC WELDING WITH FLUX-CORED WIRES CONTAINING A REACTION MIXTURE OF $\mathrm{B}_{\mathbf{4}} \mathrm{C} / \mathrm{MO}$
}

P.P r y s y a z h $\mathbf{n}$ y u k
PhD, Associate Professor*
E-mail: pavlo1752010@gmail.com

L. S h l a pak

Doctor of Technical Sciences, Professor*

O. I vanov

Postgraduate student

Cycle Commission of Applied Mechanics

College of Electronic Devices IFNTUOG

Vovchynetska str., 223, Ivano-Frankivsk, Ukraine, 76006

S. Korniy

Doctor of Technical Sciences, Senior Researcher, Head of Department

Department of Corrosion and Corrosion Protection Karpenko Physico-Mechanical Institute of the National Academy of Sciences of Ukraine

Naukova str., 5, Lviv, Ukraine, 79060

L. L u t s a k

$\mathrm{PhD}$, Production Director

Limited Liability Company Interdisciplinary Research and Production Center "Epsilon LTD"

Makukhy str., 2, Ivano-Frankivsk, Ukraine, 76014

M. B u rd a

Associate Professor*

I. H n a t e n k o

$\mathrm{PhD}$, Senior Researcher

Department of Cemented Carbides and

Composite Materials Production Technology

V. Bakul Institute for Superhard Materials of the National Academy of Sciences of Ukraine

Avtozavodska str., 2, Kyiv, Ukraine, 04074

V. Y u r k i v

Lead Engineer

Department of Physical and Chemical Processes in Brazing No. 029

The E. O. Paton Electric Welding Institute of the National Academy of Sciences of Ukraine

Bozhenko str., 11 Kyiv, Ukraine, 03680

*Department of Welding

Ivano-Frankivsk National Technical University of Oil and Gas

Karpatska str., 15, Ivano-Frankivsk, Ukraine, 76019

Copyright () 2020, P. Prysyazhnyuk, L. Shlapak, O. Ivanov,

S. Korniy, L. Lutsak, M. Burda, I. Hnatenko, V. Yurkiz

This is an open access article under the CC BY license (http://creativecommons.org/licenses/by/4.0)
1. Introduction

Molybdenum borides $\left(\mathrm{MoB}_{3}, \mathrm{Mo}_{1-x} \mathrm{~B}_{3}, \mathrm{MoB}_{4}, \mathrm{Mo}_{2} \mathrm{~B}_{5}\right.$, $\mathrm{MoB}, \mathrm{MoB}_{2}$ ) are a group of superhard materials that are promising in the application of wear-resistant coatings through a combination of hardness and ductility. According to data from the theoretical and experimental studies, the estimated chemical hardness and hardness at nano 
indentation for the Mo borides are in the range from 26 to $38 \mathrm{GPa}$.

In addition, the compounds of molybdenum are characterized by the complete wetting by metals from the group of iron while the dissolution of Mo in small quantities contributes to the increased mechanical properties and heat treatment conditions for the low-carbon steels alloyed by boron [3].

Such a set of properties in the molybdenum borides makes them promising materials for the application of coatings intended for operation in an abrasive environment where the presence of dynamic loads is allowed. This is especially relevant for the working surfaces of equipment in the woodworking, brick and coal industries, earth digging equipment, etc.

The main factor that inhibits the obtaining of coatings based on the alloys of iron and molybdenum borides in the form of separate inclusions, similar to hardfacing alloys the $\mathrm{Fe}-\mathrm{Cr}-\mathrm{C}$ and $\mathrm{Fe}-\mathrm{W}-\mathrm{C}$ systems, is their low thermodynamic stability in the systems with iron. This is evidenced by the data given in work [4] that reports a study into the structure and equilibrium phase composition of alloys from the Fe-Mo-B system in a wide range of concentrations of B and Mo (to 32 and 34 at. \%, respectively). The results from X-ray phase analysis and microscopic studies found no structure of the alloys of the $\mathrm{Mo}_{x} \mathrm{~B}_{y}$ type compounds over the entire concentration range. In this case, the main indicated phase of these alloys was a $\mathrm{FeMo}_{2} \mathrm{~B}_{2}$ compound, which is mainly included in the composition of the ternary eutectics with $\mathrm{Fe}_{2} \mathrm{~B}$ and austenite.

Thus, the formation of $\mathrm{Mo}_{x} \mathrm{~B}_{y}$ in the iron-based coatings is possible only when using such application techniques that would provide for a composite-like structure. Among them, a promising method is the flux-cored arc welding (FCAW) by electrodes filled with a powder mixture of $\mathrm{Me}^{+} \mathrm{B}_{4} \mathrm{C}$, which was used previously for the in situ formation in the surface layer of $\mathrm{TiB}_{2}$ and $\mathrm{TiC}[5]$.

The high microhardness of molybdenum borides and their positive influence (at a slight dissolution) on the properties of steels make their application promising as the components of hardfacing materials. The study of such materials implies the development of new wear-resistant coatings with a composite structure, which is relevant for materials science and tribology.

\section{Literature review and problem statement}

Among the compounds of refractory metals, obtained in situ from the powder mixtures of $\mathrm{Me}+\mathrm{B}_{4} \mathrm{C}$, the $\mathrm{Ti}-\mathrm{B}_{4} \mathrm{C}$ system has remained the most studied one until now. The result of the components' interaction in the specified system comes down to obtaining the grains of $\mathrm{TiB}_{2}$ and $\mathrm{TiC}$ in pure form or in the form of inclusions in the matrix from the selected alloy. Paper [6] demonstrated the possibility of forming a surface layer, strengthened in situ by the particles of $\mathrm{TiB}_{2}$ and $\mathrm{TiC}$ during a reaction welding by friction at stirring by adding $\mathrm{B}_{4} \mathrm{C}$ to the weld zone. The hardness of the titanium alloy after such treatment increases by almost 2 times. $\mathrm{TiB}_{2}$ and $\mathrm{TiC}$, synthesized in situ, were also found at the laser cladding of coatings from a mixture of $\mathrm{Ni}, \mathrm{Cr}$, Ti powders and $\mathrm{B}_{4} \mathrm{C}$. The coating has a distinct heterophase structure and a microhardness of $\sim 12 \mathrm{GPa}$ [7]. The similar character of the formation of titanium compounds is also observed at the electric arc deposition of coatings by a non-fusible (tungsten) electrode of the preliminary applied $\mathrm{Ti}$ and $\mathrm{B}_{4} \mathrm{C}$ mixtures with a different component ratio (5:1, 3:1, and $3: 2)$ [8]. In this case, the ratio of the components does not affect the fundamental possibility of the formation of titanium compounds but only the quality of the bonding between the coating and the base. The bond quality between the coating and the base is improved while increasing the Ti content and the abrasion resistance is naturally increased by increasing the $\mathrm{B}_{4} \mathrm{C}$ content. Study [9] investigated composites with a titanium matrix produced by a hot-pressing method from a mixture of fine powders $\mathrm{TiC}$ and $\mathrm{TiB}_{2}$ and obtained in situ from the reaction mixture of $\mathrm{Ti}$ and $\mathrm{B}_{4} \mathrm{C}$. It is important to note that the comparative analysis of the composites' properties, obtained at the same phase ratio, shows that the abrasive durability of composites, obtained in situ, is higher by $\sim 1.5$ times.

Other refractory metals (except Ti) in the mixtures with boron carbide are used primarily to produce the composites and pure compounds in situ. The authors of [10] obtained $\mathrm{ZrB}_{2}, \mathrm{ZrC}$, and a ternary boride phase of $\mathrm{ZrCo}_{3} \mathrm{~B}_{2}$ from a mixture of powders of $\mathrm{Co}, \mathrm{Zr}$, and $\mathrm{B}_{4} \mathrm{C}$ by the method of reaction combustion synthesis at the temperatures of $\sim 1,200{ }^{\circ} \mathrm{C}$. The results of the $\mathrm{X}$-ray phase analysis revealed no traces of the starting $\mathrm{B}_{4} \mathrm{C}$ among the products of interaction, indicating the completeness of the reaction course. Similarly, the course of the self-propagating high-temperature synthesis in the $\mathrm{Cu}-\mathrm{Zr}-\mathrm{B}-\mathrm{C}$ system produced the particles of $\mathrm{ZrB}_{2}$ and $\mathrm{ZrC}$ in the copper matrix [11]. The in situ formed $\mathrm{VB}_{2}$ and $(\mathrm{Ti}, \mathrm{V}) \mathrm{B}_{2}$ were found by the authors of [12] when obtaining the $\mathrm{B}_{4} \mathrm{C}$-based composites, by the hot-pressing method involving the powders of $\mathrm{B}_{4} \mathrm{C}, \mathrm{TiH}_{2}$, and $\mathrm{VC}$ at $2,200{ }^{\circ} \mathrm{C}$. In [13], $\mathrm{VBx}$ and $\mathrm{VC}$ were obtained in the structure of coatings with a microhardness of $\sim 12 \mathrm{GPa}$, due to the interaction between ferrovanadium and $\mathrm{B}_{4} \mathrm{C}$. The authors of [14] investigated the influence exerted by adding $\mathrm{Nb}$ and $\mathrm{B}_{4} \mathrm{C}$ in the same quantity $(\sim 5 \%)$ on the structure and wear resistance of coatings made from high-chromium Fe alloys obtained by laser cladding. The results showed that only the carbide phase of $\mathrm{Nb}$ forms in the interaction between $\mathrm{Nb}$ and $\mathrm{B}_{4} \mathrm{C}$, and, instead of the predicted $\mathrm{NbB}_{2}$ phase, a $\mathrm{Fe}_{2} \mathrm{~B}$-based phase is formed.

There are no literary data on using the Mo- $\mathrm{B}_{4} \mathrm{C}$ system in a pure form for arc welding coatings. According to [14], when obtaining coatings from the $\mathrm{Fe}-\mathrm{Ti}-\mathrm{Mo}-\mathrm{B}-\mathrm{C}$ system by using a method of the laser application of a mixture of powders of ferroalloys and $\mathrm{B}_{4} \mathrm{C}$ an increase in the Mo content results in a significant refinement of the grain structure. When one increases the content of Mo up to $\sim 8 \%$ of weight the grain sizes of $(\mathrm{Ti}, \mathrm{Mo}) \mathrm{B}_{2}$ and $(\mathrm{Ti}, \mathrm{Mo}) \mathrm{C}$ are reduced from $\sim 100$ to $\sim 10 \mu \mathrm{m}$, while the coating hardness increases from 900 to $1,300 \mathrm{HV}$. One of the arguments confirming the possibility of the formation of molybdenum borides of various composition from the reaction mixture of $\mathrm{Mo}+\mathrm{B}_{4} \mathrm{C}$ is given in work [15], which shows the fundamental possibility of obtaining a series of $\mathrm{Mo}_{x} \mathrm{~B}_{y}$ compounds by heating the $\mathrm{Mo} / \mathrm{B}_{4} \mathrm{C}$ mixture over a temperature range of 1,273-1,673 K.

Our analysis of the scientific literature reveals that the main issue in the formation of coatings based on iron strengthened by $\mathrm{Mo}_{x} \mathrm{~B}_{y}$ in the form of separated inclusions, similar to $\mathrm{TiB}_{2}[6-9]$, is the interaction within the $\mathrm{Fe}-\mathrm{Mo}_{x}$ $\mathrm{B}_{y}$ system. Its result is the formation of a $\mathrm{FeMo}_{2} \mathrm{~B}_{2}$ phase, which is part of the eutectics with iron, thereby forming a structure that is not optimal in terms of wear resistance, 
compared to composite [11-13]. Therefore, the conventional methods of hardfacing involving electrode materials in the form of master alloys or ferroalloys, which imply the complete melting and recrystallization of the alloy, are not rational for coatings from the $\mathrm{Fe}-\mathrm{Mo}_{x} \mathrm{~B}_{y}$ system. A composite structure can be obtained, in particular, by combining the in situ formation and arc welding implying the use of the reaction mixtures of $\mathrm{Mo}$ and $\mathrm{B}_{4} \mathrm{C}$. Under such conditions, given the high rate of the structure-forming processes, the interaction degree in the $\mathrm{Fe}-\mathrm{Mo}_{x} \mathrm{~B}_{y}$ system is considerably minimized and, accordingly, the diffusion interaction, which is undesirable for such coatings, slows down. In addition, the hardness and wear resistance of the coatings containing hard refractory compounds synthesized in situ, are substantially higher compared to conventional coatings based on the alloys from the $\mathrm{Fe}-\mathrm{Cr}(\mathrm{B})-\mathrm{C}$ system. The abrasion resistance of the composites containing the in situ formed compounds is substantially higher compared with the composites of a similar phase composition obtained with the use of ready-made compounds. This predetermines the development of new chromium-free materials for hardfacing with the relatively high hardness, crack resistance, and cyclic stability, which could be applied by electric arc methods based on simple technology.

\section{The aim and objectives of the study}

The aim of this study was to develop new flux-cored electrode materials for hardfacing by arc welding based on the $\mathrm{Fe}-\mathrm{Mo}-\mathrm{B}-\mathrm{C}$ alloying system by using the $\mathrm{Mo} / \mathrm{B}_{4} \mathrm{C}$ reaction mixture intended for the in situ formation of molybdenum compounds with boron with enhanced microhardness.

To accomplish the aim, the following tasks have been set:

- to assess, by using the Fe-Mo-B-C system thermodynamic analysis, the phase composition of alloys in the concentration and temperature ranges that correspond to the formation of FCAW coatings from the $\mathrm{Mo} / \mathrm{B}_{4} \mathrm{C}$ mixtures;

- to establish the phase composition, structure, and mechanism of the structure formation of a surface layer at FCAW with a reaction mixture of $\mathrm{Mo} / \mathrm{B}_{4} \mathrm{C}$;

- to determine the hardness and wear resistance of coatings and provide practical recommendations regarding their use.

\section{The materials and procedure to study the structure and properties of arc welding coatings applied by electrodes with a reaction mixture of $\mathrm{Mo} / \mathrm{B}_{4} \mathrm{C}$}

The flux-cored electrodes were fabricated at a machine designed at the Institute of Electric Welding named after Paton in the form of single-core powder wire made from the low-carbon steel of brand 08kp GOST 3559-75, filled with a mixture of the powders of Mo (grade MPCh) and $\mathrm{B}_{4} \mathrm{C}$ (brand 2V ISO 9001:2008) with an average particle size of $\sim 5$ and $\sim 20 \mu \mathrm{m}$, respectively. The powders of Mo and $\mathrm{B}_{4} \mathrm{C}$ were blended in a drum mixer of inertial type at ratio $4: 1$ for 24 hours. Upon mixing, the mixture was plasticized using a solution of pulver bakelite in alcohol. Next, the mixture was dried at $150-200{ }^{\circ} \mathrm{C}$ for 2 hours; it was granulated by rubbing through a sieve with a size cell of $1 \mathrm{~mm}$. To improve the technological properties of the arc welding process (the arc protection from the atmosphere, the stability of arc burning), the mixture was additionally supplemented with rutile $\left(\mathrm{TiO}_{2}\right)$ and fluoride calcium $\left(\mathrm{CaF}_{2}\right)$ in the proportion $1: 2$ and in the amount of $20 \%$ of the mixture mass. The fill factor of the ready-made flux-cored electrodes (the ratio of a charge weight to the weight of an electrode) was at the level of 0.4 . Thus, the calculated elemental composition of the surface layer was as follows, $\%$ by weight: Mo $-35 \%$; $\mathrm{B}-4 \%$; $-1 \%$. Arc welding was performed at a direct current of reverse polarity (the current magnitude is $160 \mathrm{~A}$, voltage $-30 \mathrm{~V}$ ).

The phase structure of coatings was determined based on the method of X-ray diffraction (XRD) phase analysis using the diffractometer $\mathrm{DRON}-3 \mathrm{M}$ in filtered $\mathrm{CuK}_{\alpha}$ radiation. The microstructure of coatings was determined by the method of scanning electron microscopy (SEM); the distribution of chemical elements in the structural components - by the method of energy dispersion X-ray spectroscopy (EDS) using the electron microscope Carl Zeiss EVO 40XVP, equipped with the spectrometer INCA ENERGY 350. The grain sizes were determined according to the procedure described in work [16]. The macro hardness of coatings was determined by the Rockwell method (scale C); the microhardness - by the Vickers method while loading the indenter with $50 \mathrm{~g}$. The wear resistance of coatings was determined by rubbing the cylindrical samples against a monolithic abrasive (carborundum grinding wheel) at a load of $5 \mathrm{kN}$, a slide speed of $3 \mathrm{~m} / \mathrm{s}$, and a friction path of $500 \mathrm{~m}$. For a comparative analysis of the properties of the examined materials and standard ones, we selected electrode materials from the Fe-Cr-C-B and Fe-Cr-C-B-Ti systems of brands T520 and T690, produced by the Institute of Electric Welding named after Paton.

The thermodynamic analysis of the phase equilibrium in the Fe-Mo-B-C system's polythermal cross-sections, corresponding to the coatings' composition, was performed using the Thermo-Calc and OpenCalphad software [17]. The modeling was carried out by extrapolating the thermodynamic functions of the lower order systems, specifically Fe-Mo-C [18], Fe-B-C [19], Fe-Mo-B [4], as well as the data given in work [20].

\section{Results of studying the formation of the structure of arc welding coatings from flux-cored electrodes with a reaction mixture of $\mathrm{Mo} / \mathrm{B}_{4} \mathrm{C}$}

\section{1. Thermodynamic analysis of alloys enriched with} iron from the Fe-Mo-B-C system

The polythermal cross-section of Fe-Mo-B-C (Fig. 1,a) in a concentration range that is typical for alloys from the $\mathrm{Fe}+\mathrm{B}_{4} \mathrm{C}$ system, which can be obtained by arc welding with flux-cored electrodes, belongs to the eutectic type. The stable phases in a given system are as follows: melt (L), compound $\mathrm{FeMo}_{2} \mathrm{~B}_{2}(\tau)$, the high- and low-temperature ferrite ( $\mathrm{F}$ and $\left.\mathrm{F}^{\mathrm{HT}}\right)$, austenite $(\mathrm{A})$, the lower iron boride $\left(\mathrm{Fe}_{2} \mathrm{~B}\right)$, and cementite $(\mathrm{Cem})$. The compound $\tau$ is a dominant phase of the examined alloys; it is a part of all alloys containing Fe-MoBC ${ }_{0,25}$ from 0 to 30 at. \% only in the form of the eutectic with austenitic, or in a pure form. The full-eutectic structure corresponds to composition $\sim 10$ at. \% and temperature $\sim 1500 \mathrm{~K}$. The crystallization process of a typical hypo-eutectic alloy (Fig. 1, $b$ ) begins with the crystallization of high-temperature ferrite and its subsequent transformation to austenite. It exists in equilibrium with a melt 
to a temperature of $\sim 1,500 \mathrm{~K}$, at which a eutectic decay of the melt occurs according to the following scheme: $\mathrm{L} \rightarrow \mathrm{A}+\tau$. Such eutectics exist in equilibrium with the melt to a temperature of $1,400 \mathrm{~K}$, at which the formation of the ternary eutectics $\mathrm{A}+\tau+\mathrm{Fe}_{2} \mathrm{~B}$ occurs. This structure is stable over a sufficiently wide temperature range up to the temperatures of 1,100 and $1,000 \mathrm{~K}$, at which austenite transforms to ferrite followed by its eutectic decay, respectively. The eutectic decomposition of austenite is accompanied by the disappearance of the $\mathrm{Fe}_{2} \mathrm{~B}$ phase.

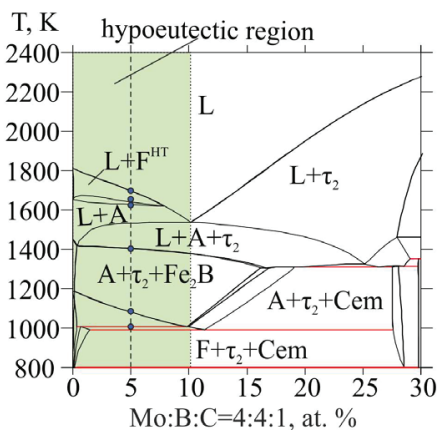

a

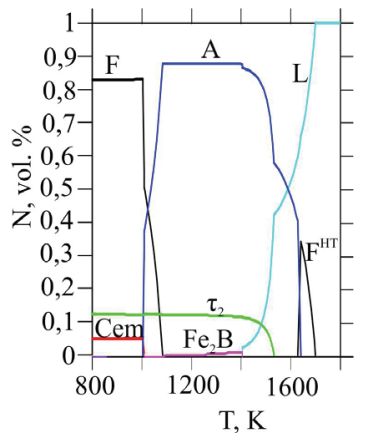

b
Fig. 1. Results of calculating the phase equilibrium of the $\mathrm{Fe}-\mathrm{Mo}-\mathrm{B}-\mathrm{C}$ system over the following range: $a-\mathrm{a}$ fragment of the polythermal cross-section of the $\mathrm{Fe}-\mathrm{Mo}-\mathrm{B}-\mathrm{C}$ system for alloys enriched with iron along the $\mathrm{Fe}-\mathrm{MoBC}_{0,25}$ line; $b-$ temperature dependence of the equilibrium amount of phases of a typical hypo-eutectic alloy

Consequently, the equilibrium structure of the hypo-eutectic alloys in the $\mathrm{Fe}-\mathrm{MoBC}_{0,25}$ system consists of the eutectic $\mathrm{F}+\tau$ (at the moment of formation of $\mathrm{A}+\tau$ ), the eutectoid $(\mathrm{F}+\mathrm{Cem})$, and ferrite F. Because of the $\tau$ phase, Mo borides are not stable over the entire considered range of concentrations, so it is impossible to obtain, when using the traditional methods of arc welding, a structure with the inclusion of molybdenum borides in the ferrite or austenite matrices.

5. 2. The structure and phase composition of arc welding coatings of the $\mathrm{Fe}-\mathrm{Mo}-\mathrm{B}-\mathrm{C}$ system obtained from the reaction mixture of $\mathrm{B}_{4} \mathrm{C} / \mathrm{Mo}$

An analysis of the microstructure of a surface layer obtained by FCAW using the electrodes with a powder mixture of $\mathrm{B}_{4} \mathrm{C} / \mathrm{Mo}$ (Fig. 2, $a$ ) shows that it has a heterophase structure. The main structural components of the coating are the faceted grains with a cross-section of the triangular, rectangular, hexagonal shape, the lamellar eutectics that surrounds the specified grains, and a single-phase alloy matrix. The shape of the grains' cross-sections is typical for the compounds forming a hexagonal syngonium. The morphological features of the eutectic correspond to the eutectic $\left(\mathrm{FeMo}_{2} \mathrm{~B}_{2}\right.$ +austenite) identified in study [4] in the Fe-Mo-B alloys. Based on the results of XRD phase analysis, three main phases were identified:
$\mathrm{Mo}_{3} \mathrm{~B}_{0.91}$ with a hexagonal lattice, low-temperature ferrite, and $\mathrm{FeMo}_{2} \mathrm{~B}_{2}$. the phases' lattice parameters are as follows: $\mathrm{Mo}_{3} \mathrm{~B}_{0.91}-a=5.317$ and $c=6.103 \AA-\left(\mathrm{P} 6_{3} / \mathrm{mmc}\right.$ space group); ferrite $-a=2.842 \AA$ (Im-3m space group); $\mathrm{FeMo}_{2} \mathrm{~B}_{2}-a=5.76$ and $c=3.198 \AA$ ( $\mathrm{P} 4 / \mathrm{mbm}$ space group). In addition, minor traces of cementite were found, as well as of the $\mathrm{Fe}_{2} \mathrm{~B}$ and $\mathrm{Mo}_{2} \mathrm{CB}$ compounds. An analysis of the distribution of chemical elements over the area (Fig. 3) shows that the faceted grains (white phase) contain both a high content of Mo and $\mathrm{B}$ in the almost complete absence of Fe traces. This, together with the results of XRD phase analysis, and the analysis of the grains' shapes, makes it possible to identify the specified phase as molybdenum tetraboride $\mathrm{MoB}_{4}$. The eutectics around the $\mathrm{MoB}_{4}$ grains contain the high content of $\mathrm{Fe}, \mathrm{Mo}$, and $\mathrm{B}$ at the same time. Taking into consideration the nature of the phase equilibrium in the Fe-Mo-B-C system and the results from XRD phase analysis, it is a eutectic mixture of $\mathrm{FeMo}_{2} \mathrm{~B}_{2}(\tau)$ and ferrite. The matrix of the alloy is ferrite with the increased lattice parameter due to the dissolution of Mo and C.

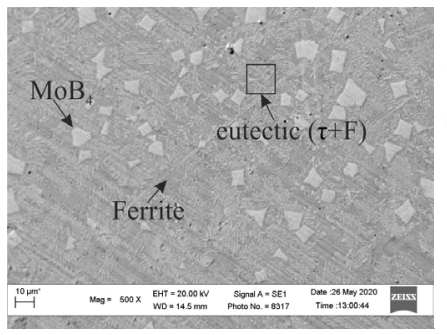

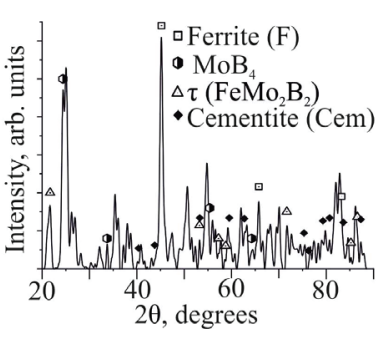

$b$
Fig. 2. Results from an analysis of the structure and phase composition of a coating with electrodes with the reaction mixture of $\mathrm{B}_{4} \mathrm{C} / \mathrm{Mo}: a-$ the microstructure of a surface layer $(\times 500)$; $b-\mathrm{X}$-ray diffraction pattern of the coating

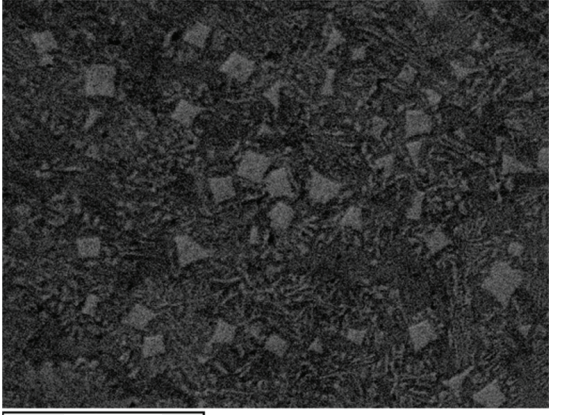

$100 \mu \mathrm{m}$

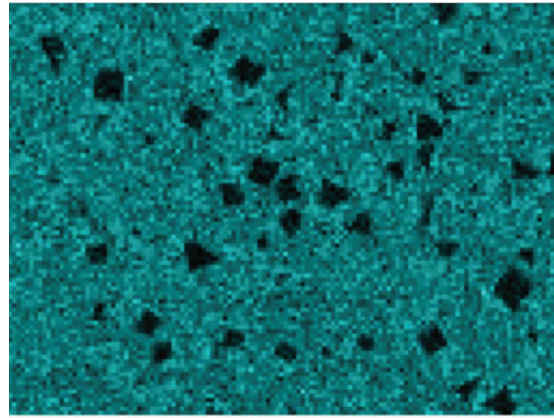

Fe Kal

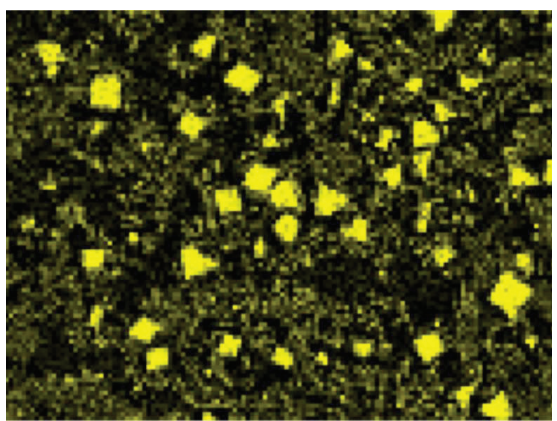

Mo La1

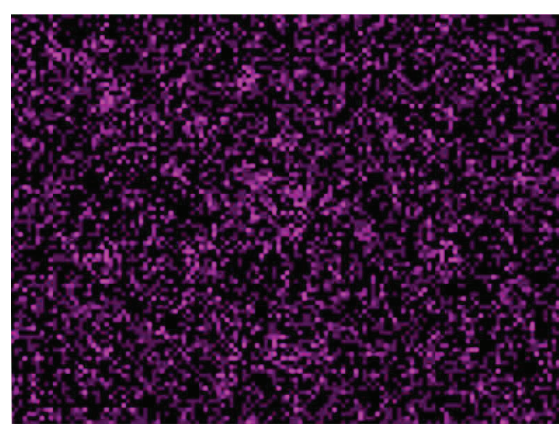

B Kal 2

Fig. 3. Results of EDS analysis of the coating of the Fe-Mo-B-C system: $a-$ the area of analysis; $b$ - the distribution of $\mathrm{Fe} ; c-$ the distribution of Mo; $d$ - the distribution of $\mathrm{B}$ 
The presence of ferrite in the form of a separate structural component (matrix) of the coating assumes the presence of a ductility reserve, and, consequently, promotes the increase of its impact stability.

\section{3. The hardness and wear resistance of FCAW} coatings made from flux-cored electrodes filled with a reaction mixture of $\mathrm{B}_{4} \mathrm{C} / \mathrm{Mo}$

The results of measuring wear resistance of the obtained coatings show that their resistance when rubbing against a fixed abrasive is substantially (by $2-2.5$ times) higher compared with standard high-chromium materials for arc welding (Fig. 4).

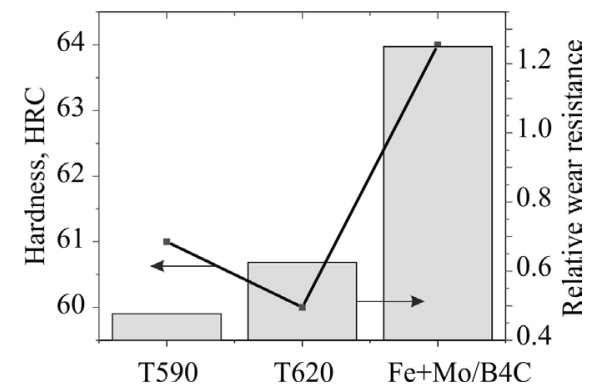

Fig. 4. Results of a comparative analysis of wear resistance of electrode materials with a reaction mixture of $\mathrm{B}_{4} \mathrm{C} / \mathrm{Mo}$ and standard materials for arc welding

The high wear resistance of the obtained coatings is primarily due to the higher microhardness of molybdenum borides compared to the boride and carbide phases of chromium, as well as a finer eutectic structure and the presence of a ferrite matrix that strongly holds carbide grains.

\section{Discussing the results of forming the structure of arc welding coatings from flux-cored electrodes with a reaction mixture of $\mathrm{Mo} / \mathrm{B}_{4} \mathrm{C}$}

Our generalization of the results of the thermodynamic analysis (Fig. 1), the structure and phase composition (Fig. 2, 3), shows that, when applying coatings of the $\mathrm{Fe}-\mathrm{Mo} / \mathrm{B}_{4} \mathrm{C}$ system, one observes three main zones: reaction, melting, and solidification (Fig. 5). In the reaction zone, under the influence of an electric arc, there is the reactive combustion synthesis similar to the type of self-propagating high-temperature synthesis, ending by the in situ formation of $\mathrm{MoB}_{4}$. Given the low thermodynamic stability of Mo carbides, they do not form under these conditions, the free carbon is released instead, which partially interacts with atmospheric oxygen forming $\mathrm{CO}_{2}$, which serves as the arc protection function. In the zone of melting, there is a partial dissolution of $\mathrm{Mo}$ and $\mathrm{B}$ from $\mathrm{MoB}_{4}$ in iron. This leads to that the melt composition acquires such a concentration that corresponds to the hypo-eutectic alloys (Fig. 1). This leads to the that in the next zone of solidification there is the crystallization of phases in the following sequence: high-temperature ferrite, austenite, eutectic (austenite+ $+\mathrm{FeMo}_{2} \mathrm{~B}_{2}$ ). Following the process of the eutectic austenite decomposition, the structure consists of three phases: ferrite, $\mathrm{FeMo}_{2} \mathrm{~B}_{2}$ and $\mathrm{MoB}_{4}$.

The structure, obtained as a result of the proposed process of arc welding, is favorable in terms of ensuring the abrasive wear resistance since it represents an inclusion of the superhard compound $\left(\mathrm{MoB}_{4}\right)$ in a ductile matrix. The materials obtained could be used to replace standard electrode materials from the $\mathrm{Fe}-\mathrm{Cr}-\mathrm{C}$ system for severe operating conditions, in particular, when hardfacing the working surfaces of equipment for mining and processing coal, in the brick industry, earth digging equipment, etc.

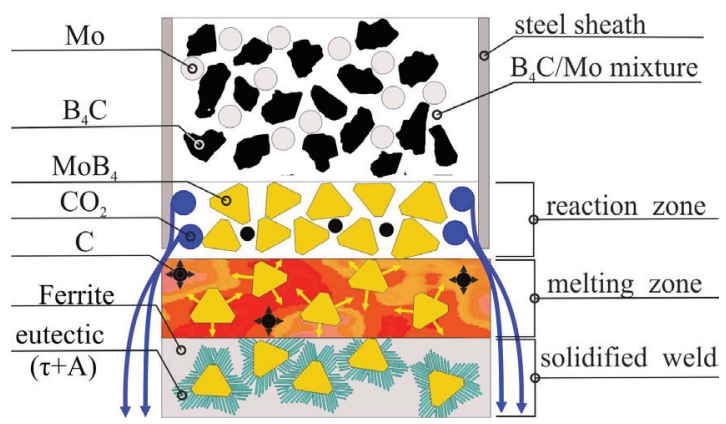

Fig. 5. Schematic formation of a surface layer when welding with flux-cored electrode materials with a reaction mixture of $\mathrm{Mo}_{\mathrm{O}} / \mathrm{B}_{4}$

The main restriction for the application of the developed coatings is the inadmissibility of re-melting the applied layer or its operation at elevated temperatures. Such exposure would lead to the transition of the structure into an equilibrium state with the eutectic structure as a result of dissolving the grains of $\mathrm{MoB}_{4}$ in ferrite. In addition, when applying powders with a reaction mixture, it is necessary to specially prepare the powders, which implies providing for their flowability by introducing polymeric binders.

Further studies need to investigate the impact of other refractory metals that form the solid boride phases, such as $\mathrm{Ti}, \mathrm{V}, \mathrm{Zr}$ in the mixtures with $\mathrm{Mo}$ and $\mathrm{B}_{4} \mathrm{C}$. The main difficulty in the subsequent development of such coatings is the complete elimination of the ferrite-boride eutectics by rationally selecting the composition of powdered mixtures (starting reagents).

\section{Conclusions}

1. Based on the calculated polythermal cross-section of alloys in the Fe-Mo-B-C system along the $\mathrm{Fe}-\mathrm{MoBC}_{0.25}$ line, the main structural component of such alloys, which ensures wear resistance, is the eutectics ferrite $+\mathrm{FeMo}_{2} \mathrm{~B}_{2}$. Dissolving molybdenum borides in ferrite under conditions of arc welding leads to the formation, in a surface layer, of the hypo-eutectic alloy structures.

2. When applying coatings of the Fe-Mo-B-C system by the method of FCAW using flux-cored electrode materials containing a reaction mixture of $\mathrm{B}_{4} \mathrm{C} / \mathrm{Mo}$, there is the in situ formation of the inclusions of a metastable superhard phase of $\mathrm{MoB}_{4}$. Its morphology represents the uniformly spaced faceted grains, which coexist with the pre-eutectic alloys, rich in iron, of the Fe-Mo-B-C system.

3. The hardness of coatings made from flux-cored electrodes containing the in situ formed are $\mathrm{MoB}_{4}$ is at the level of 63-65 HRC. Their wear resistance, when rubbed against a monolithic abrasive, exceeds the wear resistance of standard alloys from the Fe-Cr-C and Fe-Cr-B-C systems by $2-2.5$ times. Such coatings are recommended for use when hardfacing parts operated under the conditions of enhanced abrasive wear, in particular in the coal mining, brick, and processing industries. 


\section{References}

1. Tang, H., Gao, X., Zhang, J., Gao, B., Zhou, W., Yan, B. et. al. (2019). Boron-Rich Molybdenum Boride with Unusual Short-Range Vacancy Ordering, Anisotropic Hardness, and Superconductivity. Chemistry of Materials, 32 (1), 459-467. doi: https://doi.org/ 10.1021/acs.chemmater.9b04052

2. Liang, Y., Yuan, X., Fu, Z., Li, Y., Zhong, Z. (2012). An unusual variation of stability and hardness in molybdenum borides. Applied Physics Letters, 101 (18), 181908. doi: https://doi.org/10.1063/1.4764547

3. Mohrbacher, H. (2018). Property Optimization in As-Quenched Martensitic Steel by Molybdenum and Niobium Alloying. Metals, 8 (4), 234. doi: https://doi.org/10.3390/met8040234

4. Ou Yang, X., Yin, F., Hu, J., Zhao, M., Liu, Y. (2017). Experimental investigation and thermodynamic calculation of the B-Fe-Mo ternary system. Calphad, 59, 189-198. doi: https://doi.org/10.1016/j.calphad.2017.10.007

5. Lutsak, D. L., Prysyazhnyuk, P. M., Karpash, M. O., Pylypiv, V. M., Kotsyubynsky, V. O. (2016). Formation of structure and properties of composite coatings $\mathrm{TiB}_{2}$-TiC-Steel obtained by overlapping of electric-arc surfacing and self-propagating High-Temperature Synthesis. Metallofizika i Noveishie Tekhnologii, 38 (9), 1265-1278. doi: https://doi.org/10.15407/mfint.38.09.1265

6. Wang, T., Gwalani, B., Shukla, S., Frank, M., Mishra, R. S. (2019). Development of in situ composites via reactive friction stir processing of Ti-B ${ }_{4} \mathrm{C}$ system. Composites Part B: Engineering, 172, 54-60. doi: https://doi.org/10.1016/j.compositesb.2019.05.067

7. Han, T., Xiao, M., Zhang, Y., Shen, Y. (2019). Laser cladding composite coatings by Ni-Cr-Ti-B4C with different process parameters. Materials and Manufacturing Processes, 34 (8), 898-906. doi: https://doi.org/10.1080/10426914.2019.1605172

8. Tijo, D., Masanta, M. (2019). Effect of Ti/B4C ratio on the microstructure and mechanical characteristics of TIG cladded TiC-TiB ${ }_{2}$ coating on Ti-6Al-4V alloy. Journal of Materials Processing Technology, 266, 184-197. doi: https://doi.org/10.1016/ j.jmatprotec.2018.11.005

9. Yi, M., Zhang, X., Liu, G., Wang, B., Shao, H., Qiao, G. (2018). Comparative investigation on microstructures and mechanical properties of $(\mathrm{TiB}+\mathrm{TiC}) / \mathrm{Ti}-6 \mathrm{Al}-4 \mathrm{~V}$ composites from $\mathrm{Ti}_{4} \mathrm{~B}_{4} \mathrm{C}-\mathrm{C}$ and $\mathrm{Ti}-\mathrm{TiB}_{2}-\mathrm{TiC}$ systems. Materials Characterization, 140, $281-289$. doi: https://doi.org/10.1016/j.matchar.2018.04.010

10. Zhang, M., Huo, Y., Huang, M., Fang, Y., Zou, B. (2015). In situ synthesis and formation mechanism of ZrC and ZrB 2 by combustion synthesis from the Co-Zr-B4C system. Journal of Asian Ceramic Societies, 3 (3), 271-278. doi: https://doi.org/10.1016/ j.jascer.2015.05.005

11. Zhang, M., Huo, Y., Huang, M., Fang, Y., Wang, G. (2015). The effect of B4C particle size on the reaction process and product in the Cu-Zr-B4C system. Journal of Asian Ceramic Societies, 3 (1), 38-43. doi: https://doi.org/10.1016/j.jascer.2014.10.006

12. Kaidash, O. N., Turkevich, V. Z., Ivzhenko, V. V., Itsenko, P. P., Tkach, V. N. (2018). The Influence of in situ Formed TiB ${ }_{2}-$ VB $_{2}$ Borides on the Structure and Properties of Hot-Pressed B4C-(TiH2-VC) Ceramic System. Journal of Superhard Materials, 40 (6), 365-373. doi: https://doi.org/10.3103/s1063457618060011

13. Qu, K. L., Wang, X. H., Wang, Z. K. (2016). Characterization of VC-VB particles reinforced Fe-based composite coatings produced by laser cladding. Surface Review and Letters, 23 (04), 1650019. doi: https://doi.org/10.1142/s0218625x16500190

14. Zhang, M., Luo, S. X., Liu, S. S., Wang, X. H. (2018). Effect of Molybdenum on the Wear Properties of (Ti,Mo)C-TiB ${ }_{2}-\mathrm{Mo}_{2} \mathrm{~B}$ Particles Reinforced Fe-Based Laser Cladding Composite Coatings. Journal of Tribology, 140 (5). doi: https://doi.org/10.1115/1.4039411

15. Wang, Y., Zhang, H., Jiao, S., Chou, K., Zhang, G. (2020). A facile pathway to prepare molybdenum boride powder from molybdenum and boron carbide. Journal of the American Ceramic Society, 103 (4), 2399-2406. doi: https://doi.org/10.1111/jace.16984

16. Shlapak, L. S., Shihab, T., Prysyazhnyuk, P. M., Yaremiy, I. P. (2016). Structure Formation of the Chromium Carbide-Based Cermet with Copper-Nickel-Manganese Binder. Metallofizika i Noveishie Tekhnologii, 38 (7), 969-980. doi: https://doi.org/10.15407/ mfint.38.07.0969

17. Sundman, B., Kattner, U. R., Palumbo, M., Fries, S. G. (2015). OpenCalphad - a free thermodynamic software. Integrating Materials and Manufacturing Innovation, 4 (1), 1-15. doi: https://doi.org/10.1186/s40192-014-0029-1

18. Hillert, M., Qiu, C. (1992). A reassessment of the Fe-Cr-Mo-C system. Journal of Phase Equilibria, 13 (5), $512-521$. doi: https://doi.org/10.1007/bf02665764

19. Miettinen, J., Visuri, V. V., Farbitius, T., Vassilev, G. (2020). Thermodynamic Description of Ternary Fe-B-X Systems. Part 7: Fe-B-C. Archives of Metallurgy and Materials, 65 (2), 923-933. doi: http://doi.org/10.24425/amm.2020.132840

20. Shihab, T., Prysyazhnyuk, P., Semyanyk, I., Anrusyshyn, R., Ivanov, O., Troshchuk, L. (2020). Thermodynamic Approach to the Development and Selection of Hardfacing Materials in Energy Industry. Management Systems in Production Engineering, 28 (2), 84-89. doi: https://doi.org/10.2478/mspe-2020-0013 